\title{
The Metabolic Syndrome and Cognitive Performance: The Northern Manhattan Study
}

\author{
Julio R. Vieira ${ }^{a, b}$ Mitchell S.V. Elkind ${ }^{a, b}$ Yeseon Park Moon ${ }^{a}$ Tatjana Rundek $^{e}$ \\ Bernadette Boden-Albala ${ }^{a, d}$ Myunghee C. Paik ${ }^{c}$ Ralph L. Sacco ${ }^{e, f}$ \\ Clinton B. Wright ${ }^{\mathrm{e}}$ \\ ${ }^{\text {a } D e p a r t m e n t ~ o f ~ N e u r o l o g y, ~ C o l l e g e ~ o f ~ P h y s i c i a n s ~ a n d ~ S u r g e o n s, ~ C o l u m b i a ~ U n i v e r s i t y, ~ a n d ~ D e p a r t m e n t s ~ o f ~}{ }^{b}$ Epidemiology, \\ 'Biostatistics, and d Socio-Medical Sciences, Mailman School of Public Health, Columbia University, New York, N.Y., \\ eEvelyn F. McKnight Brain Institute and Departments of Neurology, Epidemiology and Public Health, and \\ ${ }^{f}$ Department of Genetics, Miller School of Medicine, University of Miami, Miami, Fla., USA
}

\section{Key Words}

Cognitive performance $\cdot$ Cognitive impairment •

Vascular dementia - Vascular cognitive impairment .

Cerebrovascular disorders $\cdot$ Metabolic syndrome

\begin{abstract}
Background: The metabolic syndrome (MetS) is a risk factor for diabetes, stroke, myocardial infarction, and increased mortality, and has been associated with cognition in some populations. We hypothesized that MetS would be associated with lower Mini-Mental State Examination (MMSE) scores in a multi-ethnic population, and that MetS is a better predictor of cognition than its individual components or diabetes. Methods: We conducted a cross-sectional analysis among 3,150 stroke-free participants. MetS was defined by the modified National Cholesterol Education Program guidelines-Adult Treatment Panel III (NCEP-ATPIII) criteria. Linear regression and polytomous logistic regression estimated the association between MMSE score and MetS, its individual components, diabetes, and inflammatory biomarkers. Results: MetS was inversely associated with MMSE score (unadjusted $\beta=-0.67 ; 95 \% \mathrm{Cl}-0.92,-0.41$ ). Adjusting for potential confounders, MetS was associated with lower
\end{abstract}

\section{KARGER}

Fax +41613061234 E-Mail karger@karger.ch www.karger.com
(C) 2011 S. Karger AG, Basel

Accessible online at: www.karger.com/ned
MMSE score (adjusted $\beta=-0.24 ; 95 \% \mathrm{Cl}-0.47,-0.01$ ), but its individual components and diabetes were not. Those with MetS were more likely to have an MMSE score of $<18$ than a score of $\geq 24$ (adjusted OR $=1.94 ; 95 \% \mathrm{Cl} 1.26,3.01$ ). There was an interaction between MetS and race-ethnicity, such that MetS was associated with lower MMSE score among non-Hispanic whites and Hispanics but not non-Hispanic blacks. Conclusions: MetS was associated with lower cognition in a multi-ethnic population. Further studies of the effect of MetS on cognition are warranted, and should account for demographic differences. Copyright $\odot 2011$ S. Karger AG, Basel

\section{Introduction}

The metabolic syndrome (MetS) is a risk factor for diabetes, stroke, myocardial infarction [1], and increased mortality $[2,3]$. Previous studies demonstrated an association between cardiovascular risk factors (including hypertension and diabetes) and cognitive aging [4]; additionally, insulin resistance and abnormal cholesterol metabolism have been connected to memory loss and the development of Alzheimer disease and vascular dementia $[5,6]$. 
The relationship between MetS and cognition, however, remains uncertain, and appears to depend in part on demographics and levels of inflammatory biomarkers. Moreover, it is unclear if MetS is a better predictor of cognitive performance than its individual components or diabetes alone. Few studies, however, have looked separately at the MetS components individually and as a whole [7, 8]. Previous studies evaluated non-Hispanic whites, and only one study assessed a Hispanic population composed of Mexican-Americans [9]. None of the previous studies evaluated the cognitive effects of MetS among Caribbean Hispanics, a group for whom MetS is quite prevalent [10].

The purpose of this study was to investigate the relationship between MetS and cognitive performance using the Mini-Mental State Examination (MMSE) [11] in a multi-ethnic cohort. We sought, furthermore, to determine if MetS is a better predictor of cognitive performance than its individual components or diabetes, and if inflammatory biomarkers modify this association.

\section{Subjects and Methods}

\section{Cohort Selection and Evaluation}

The cohort for this analysis was derived from the participants enrolled in the Northern Manhattan Study (NOMAS) identified by random-digit dialing and recruited for an in-person assessment, as previously described [10]. Baseline cognitive assessment was performed using the 30-point MMSE in English and Spanish, depending on the participant's language spoken at home. The study was approved by the Institutional Review Board at Columbia University and the University of Miami and participants provided informed consent.

\section{Metabolic Syndrome}

MetS was defined by the modified National Cholesterol Education Program guidelines-Adult Treatment Panel III (NCEPATPIII) criteria represented by the presence of 3 or more of the 5 components linked to insulin resistance: (1) waist circumference $\geq 102 \mathrm{~cm}$ in men and $\geq 88 \mathrm{~cm}$ in women; (2) triglycerides $\geq 150$ $\mathrm{mg} / \mathrm{dl}$; (3) high-density lipoprotein (HDL) $<40 \mathrm{mg} / \mathrm{dl}$ in men and $<50 \mathrm{mg} / \mathrm{dl}$ in women; (4) fasting plasma glucose $\geq 100 \mathrm{mg} / \mathrm{dl}$, and (5) systolic blood pressure $\geq 130 \mathrm{~mm} \mathrm{Hg}$, or diastolic blood pressure $\geq 85 \mathrm{~mm} \mathrm{Hg}$. Blood pressure was based on the average of two measurements, or a subject self-reported history of hypertension, as previously described [10].

\section{Covariates}

Risk factors, behavioral and sociodemographic data that might influence cognition were collected as described in previous publications [10].

Education was defined based on whether or not high school was completed. Health insurance status was dichotomized to Medicaid/no insurance versus private insurance/Medicare, as previously described [12]. Moderate alcohol intake was defined as currently drinking $>1 \mathrm{drink} / \mathrm{month}$ and $\leq 2$ drinks/day [13].
Smoking was defined as current smokers. Physical activity was defined by the amount of leisure activity engaged in during the 10 days prior to assessment. Social support was assessed based on marital status and knowing three or more people well enough to visit with in their homes [14].

\section{Laboratory Assessments}

Fasting blood specimens were drawn at baseline into serum tubes and spun within one hour at $3000 \mathrm{~g}$ and $4^{\circ} \mathrm{C}$ for $20 \mathrm{~min}$ and immediately frozen at $-70^{\circ} \mathrm{C}$. HDL and triglyceride levels were measured using an automated spectrometer (Hitachi 705, Boehringer, Mannheim, Germany) as described previously [12]. Inflammatory marker levels were measured in batched samples and assays were performed blinded to MMSE. Serum amyloid A (SAA) and high-sensitivity $\mathrm{C}$-reactive protein (hsCRP) were measured using the BNII nephelometric assay system (Dade-Behring, Deerfield, Ill., USA) [15]. Interleukin-6 (IL-6) and tumor necrosis factor receptor 1 (TNFR1) were measured by enzyme-linked immunosorbent assays according to manufacturer instructions (BioSource International, Camarillo, Calif., USA), as previously described [16].

\section{Statistical Analyses}

Baseline characteristics were compared in relation to the MetS presence using $\chi^{2}$ tests for proportions, $t$ tests for continuous variables and Wilcoxon rank test for medians. Linear regressions were conducted to calculate $\beta$ and 95\% CIs for MMSE scores as a continuous measure, and polytomous logistic regressions with canonical link to calculate odds ratio (OR) and $95 \%$ CI for categorized MMSE. We analyzed MMSE as a continuous outcome, as well as according to categories based on previously defined MMSE thresholds [17] - MMSE score $\geq 24$ (normal, reference), MMSE score 1823 (mild to moderate cognitive impairment), and MMSE score $<18$ (severe cognitive impairment) - in order to facilitate clinical interpretation and to permit comparison with previous studies.

We used MetS as a main predictor, and the five individual components of MetS and diabetes as secondary predictors of interest.

Unadjusted and adjusted models for sociodemographic factors (age, sex, race-ethnicity, education) and additional risk factors (moderate alcohol consumption, smoking, social support, marriage status and physical activity) were constructed. Covariates were included in the models based on a priori hypotheses.

Interactions between MetS and sociodemographic factors were tested and stratified models were constructed as indicated. Further models incorporating SAA, hsCRP, TNFR1 and IL-6 were constructed to assess for independent effects of these markers, as well as interactions with MetS on MMSE score. Analyses were conducted using SAS v9.1.3 (SAS Institute, Cary, N.C., USA) and statistical significance defined as $\mathrm{p} \leq 0.05$.

\section{Results}

\section{Cohort Description}

Both data on MetS and MMSE were available for 3,150 participants. Their baseline characteristics are shown in table 1 . Mean age was $69.0 \pm 10.3$ years. There were $37 \%$ men, 53\% Hispanics, 21\% non-Hispanic whites and 24\% non-Hispanic blacks. 
Table 1. Descriptive analysis

\begin{tabular}{|c|c|c|c|c|}
\hline \multirow[t]{2}{*}{ Characteristics } & \multirow[t]{2}{*}{ Overall } & \multicolumn{2}{|l|}{ MetS } & \multirow[t]{2}{*}{ p value ${ }^{a}$} \\
\hline & & no & yes & \\
\hline $\mathrm{n}(\%)$ & 3,150 & $1,649(52.3)$ & $1,501(47.7)$ & \\
\hline \multicolumn{5}{|l|}{ Sociodemographic characteristics } \\
\hline Mean age \pm SD, years & $69.0 \pm 10.3$ & $69.4 \pm 11.0$ & $68.6 \pm 9.4$ & 0.04 \\
\hline Male & $1,180(37.5)$ & $701(22.3)$ & $479(15.2)$ & $<0.0001$ \\
\hline \multicolumn{5}{|l|}{ Race and ethnicity ${ }^{\mathrm{b}}$} \\
\hline Non-Hispanic white & $660(21.0)$ & $383(23.2)$ & $277(18.5)$ & ref. \\
\hline Non-Hispanic black & $762(24.2)$ & $447(27.1)$ & $315(21.0)$ & 0.81 \\
\hline Hispanic & $1,656(52.6)$ & $765(46.4)$ & $891(59.4)$ & $<0.0001$ \\
\hline \multicolumn{5}{|l|}{ Other risk factors } \\
\hline High school graduate & $1,450(46.0)$ & $851(27.0)$ & $598(19.0)$ & $<0.0001$ \\
\hline Medicaid or no insurance & $1,361(43.2)$ & $617(19.6)$ & $744(23.6)$ & $<0.0001$ \\
\hline Married & $1,005(31.9)$ & $537(17.0)$ & $468(14.9)$ & 0.40 \\
\hline 3 friends or more & $2,684(85.2)$ & $1,402(44.5)$ & $1,282(40.7)$ & 0.76 \\
\hline Any physical activity & $1,834(58.2)$ & $1,033(32.8)$ & $801(25.4)$ & $<0.0001$ \\
\hline Mild/moderate alcohol intake & $1,031(32.7)$ & 615 (19.5) & $416(13.2)$ & $<0.0001$ \\
\hline Current smoker & $548(17.4)$ & $295(9.4)$ & $253(8.0)$ & 0.55 \\
\hline Former smoker & $1,126(35.7)$ & $582(18.5)$ & $544(17.3)$ & 0.74 \\
\hline Never smoker & $1,475(46.8)$ & $772(24.5)$ & $703(22.3)$ & ref. \\
\hline \multicolumn{5}{|l|}{ MetS } \\
\hline Glucose $\geq 100 \mathrm{mg} / \mathrm{dl}^{\mathrm{c}}$ & $1,095(34.8)$ & $230(7.3)$ & $865(27.5)$ & $<0.0001$ \\
\hline $\mathrm{BP} \geq 130 / 85 \mathrm{~mm} \mathrm{Hg}$, or $\mathrm{HTN}^{\mathrm{d}}$ & $2,659(84.4)$ & $1,214(38.5)$ & $1,445(45.9)$ & $<0.0001$ \\
\hline Abdominal obesity ${ }^{\mathrm{e}}$ & $1,329(42.2)$ & $318(10.1)$ & $1,011(32.1)$ & $<0.0001$ \\
\hline Low $\mathrm{HDL}^{\mathrm{f}}$ & $1,702(54.0)$ & $440(14.0)$ & $1,262(40.0)$ & $<0.0001$ \\
\hline Triglycerides $\geq 150 \mathrm{mg} / \mathrm{dl}$ & $931(29.5)$ & $117(3.7)$ & $814(25.8)$ & $<0.0001$ \\
\hline History of diabetes & $686(21.8)$ & $164(5.2)$ & $522(16.6)$ & $<0.0001$ \\
\hline History of hypertension & $2,318(73.6)$ & $1,023(32.5)$ & $1,295(41.1)$ & $<0.0001$ \\
\hline \multicolumn{5}{|l|}{ Cognitive performance } \\
\hline Median MMSE score (IQR) & $27(24-29)$ & $27(25-29)$ & $27(24-29)$ & $<0.0001$ \\
\hline Non-Hispanic whites & $28(27-30)$ & $29(27-30)$ & $28(26.5-29)$ & 0.0003 \\
\hline Non-Hispanic blacks & $27(25-29)$ & $27(25-29)$ & $28(25-29)$ & 0.1031 \\
\hline Hispanics & $26(23-28)$ & $27(24-28)$ & $26(23-28)$ & 0.0007 \\
\hline
\end{tabular}

Values denote numbers with percentages in parentheses, unless otherwise indicated.

${ }^{a} t$ test for continuous and $\chi^{2}$ for dichotomous variables. ${ }^{b}$ Other race/ethnicity had 72 participants representing $2.3 \%$ of the sample. ${ }^{c}$ History of hypertension. ${ }^{d}$ Systolic $\mathrm{BP} \geq 130 \mathrm{~mm} \mathrm{Hg}$, diastolic $\geq 85 \mathrm{~mm} \mathrm{Hg}$; also includes history of hypertension (HTN). ${ }^{\text {e }}$ Abdominal obesity defined as waist $>89.41 \mathrm{~cm}$ (35.2 inches) for women or $>103.63 \mathrm{~cm}$ (40.8 inches) for men. ${ }^{\mathrm{f}} \mathrm{HDL}<50 \mathrm{mg} / \mathrm{dl}$ for women or $<40 \mathrm{mg} / \mathrm{dl}$ for men.

$\mathrm{IQR}=$ Interquartile range.

The MetS prevalence in our cohort was $47.6 \%$, and was similar among non-Hispanic whites and non-Hispanic blacks (41.9 and $41.3 \%$, respectively), but greater among Hispanics (53.8\%; $\mathrm{p}<0.0001)$. The median MMSE score was 27 (IQR: 24-29), and non-Hispanic blacks and Hispanics had lower MMSE scores than non-Hispanic whites $(\mathrm{p}<0.0001$; table 1$)$.

\section{MetS and MMSE Score}

Those with MetS had lower cognitive performance scores than those without MetS (unadjusted $\beta=-0.67$;
95\% CI $-0.92,-0.41)$. The association persisted after adjusting for age, sex, race-ethnicity, education, alcohol consumption, smoking, social support, marriage status, and physical activity $(\beta=-0.24 ; 95 \% \mathrm{CI}-0.47,-0.01$; table 2$)$. To put our estimates regarding MetS in perspective, we examined differences in MMSE score by age. Scores were lower by $0.096(\mathrm{SE}=0.006)$ points per 1 year increase in age. Thus, having MetS was associated with the equivalent of 2.5 years of cognitive aging in this cohort.

When we used categorized MMSE scores as an outcome, compared to those without MetS, those with MetS 
Table 2. MetS, individual components, diabetes and MMSE score

\begin{tabular}{|c|c|c|c|}
\hline & \multicolumn{3}{|l|}{$\Delta$ MMSE } \\
\hline & model 1 & model 2 & model 3 \\
\hline MetS & $-0.67(-0.92,-0.41)$ & $-0.28(-0.51,-0.05)$ & $-0.24(-0.47,-0.01)$ \\
\hline \multicolumn{4}{|c|}{ Adjusted for MetS individual components (abdominal obesity, blood glucose, blood pressure, triglycerides and HDL) } \\
\hline Abdominal obesity & $-0.20(-0.47,0.07)$ & $-0.04(-0.29,0.21)$ & $-0.01(-0.26,0.24)$ \\
\hline Blood pressure $\geq 130 / 85 \mathrm{~mm} \mathrm{Hg}$ & $-0.97(-1.34,-0.61)$ & $-0.07(-0.40,0.26)$ & $-0.06(-0.38,0.27)$ \\
\hline Triglycerides $\geq 150 \mathrm{mg} / \mathrm{dl}$ & $0.02(-0.28,0.33)$ & $0.03(-0.24,0.30)$ & $0.04(-0.23,0.30)$ \\
\hline Low HDL & $-0.38(-0.66,-0.10)$ & $-0.19(-0.44,0.06)$ & $-0.16(-0.42,0.09)$ \\
\hline Blood glucose $\geq 100 \mathrm{mg} / \mathrm{dl}$ & $-0.21(-0.49,0.06)$ & $-0.11(-0.36,0.13)$ & $-0.07(-0.32,0.17)$ \\
\hline \multicolumn{4}{|c|}{ Adjusted for waist, systolic blood pressure, diastolic blood pressure, triglycerides, HDL and blood glucose } \\
\hline Waist per inch & $0.008(-0.016,0.033)$ & $0.006(-0.019,0.030)$ & $0.023(-0.005,0.050)$ \\
\hline Systolic blood pressure per $\mathrm{mm} \mathrm{Hg}$ & $0.004(-0.003,0.011)$ & $0.004(-0.003,0.012)$ & $-0.017(-0.025,-0.010)$ \\
\hline Diastolic blood pressure per $\mathrm{mm} \mathrm{Hg}$ & $-0.011(-0.024,0.003)$ & $-0.011(-0.025,0.002)$ & $0.004(-0.011,0.018)$ \\
\hline Triglycerides per $\mathrm{mg} / \mathrm{dl}$ & $0.001(-0.001,0.002)$ & $0.001(-0.001,0.002)$ & $0.001(-0.001,0.003)$ \\
\hline HDL per mg/dl & $0.010(0.001,0.020)$ & $0.012(0.002,0.021)$ & $0.016(0.006,0.026)$ \\
\hline Blood glucose per mg/dl & $-0.001(-0.004,0.001)$ & $-0.001(-0.004,0.001)$ & $-0.004(-0.006,-0.001)$ \\
\hline \multicolumn{4}{|c|}{ Adjusted for MetS individual components (abdominal obesity, blood pressure, triglycerides and HDL) except blood glucose } \\
\hline Diabetes & $-0.42(-0.74,-0.10)$ & $-0.17(-0.45,0.11)$ & $-0.12(-0.40,0.17)$ \\
\hline
\end{tabular}

$\Delta$ MMSE $=$ Difference in MMSE score; 95\% CI given in parentheses.

Model 1: Unadjusted; model 2: adjusted for sociodemographics (age, sex, race/ethnicity, insurance and education); model 3: adjusted for sociodemographics, alcohol consumption, smoking, social support and physical activity.

Table 3. Mets and categories of MMSE scores

\begin{tabular}{llll}
\hline & OR $(95 \%$ CI $)$ & & \\
\cline { 2 - 4 } & model 1 & model 2 & $1.93(1.26-2.96)$ \\
MMSE score $<18$ vs. $\geq 24$ & $2.25(1.53-3.33)$ & $1.73(1.11-2.70)$ & $1.94(1.26-3.01)$ \\
MMSE score $<18$ vs. $18-23$ & $1.71(1.12-2.59)$ & $1.11(0.90-1.37)$ & $1.10(0.89-1.35)$ \\
MMSE score $18-23$ vs. $\geq 24$ & $1.32(1.10-1.59)$ & $1.78)$ \\
\hline
\end{tabular}

Model 1: Unadjusted; model 2: adjusted for sociodemographics (age, sex, race/ethnicity, insurance and education); model 3: adjusted for sociodemographics, alcohol consumption, smoking, social support and physical activity.

were more likely to have an MMSE score of $<18$ than a score of $\geq 24$ (adjusted OR $=1.94 ; 95 \%$ CI 1.26, 3.01). In unadjusted models, those with MetS also were more likely to have an MMSE score of 18-23 than a score of $\geq 24$, but this association was no longer significant after adjusting for potential confounders (adjusted OR $=1.10 ; 95 \% \mathrm{CI}$ $0.89,1.35$; table 3 ).

\section{MetS and MMSE Score by Race-Ethnicity}

There was evidence of an interaction between MetS and race-ethnicity for MMSE scores such that the MMSE score was lower for those with MetS among non-Hispan- ic whites but not non-Hispanic blacks ( $\mathrm{p}$ for interaction = $0.01)$. In stratified models, MetS was associated with lower MMSE score among Hispanics (adjusted $\beta=-0.41 ; 95 \%$ CI $-0.72,-0.10$ ) and non-Hispanic whites (adjusted $\beta=$ $-0.51 ; 95 \%$ CI $-1.01,-0.01)$, but not among non-Hispanic blacks (adjusted $\beta=0.38$; 95\% CI $-0.09,0.84$; table 4 ).

We did not find interactions by age, sex, education, or medical insurance status.

MetS Components, Diabetes, and MMSE Score

When evaluating the effects of each of the individual components of MetS, only two of the five components 
Table 4. MetS and MMSE score stratified by race-ethnicity

\begin{tabular}{lc}
\hline Race-ethnicity & Change in MMSE score $(95 \% \mathrm{CI})^{*}$ \\
\hline Hispanics & $-0.41(-0.72,-0.10)$ \\
Non-Hispanic whites & $-0.51(-1.01,-0.01)$ \\
Non-Hispanic blacks & $0.38(-0.09,0.84)$
\end{tabular}

* Adjusted for age, sex, education, insurance status, moderate alcohol consumption, smoking, social support and physical activity.

were associated with MMSE score in univariate analyses: high blood pressure $(\beta=-0.97 ; 95 \% \mathrm{CI}-1.34,-0.61)$ and low HDL $(\beta=-0.38 ; 95 \% \mathrm{CI}-0.66,-0.10)$. After adjusting for potential confounders, however, none of the individual components were associated with MMSE score (table 2). When analyzed as a continuous measure, however, HDL remained associated with MMSE score after fully adjusting for potential confounders (adjusted $\beta=$ 0.01 per mg/dl HDL; $p=0.03$ ), though other MetS components were not.

Diabetes was inversely associated with MMSE score, and this association remained after adjusting for individual components of MetS. After further adjusting for other potential confounders, however, the relationship was no longer significant (adjusted $\beta=-0.12$; 95\% CI $-0.40,0.17$; table 2).

\section{Inflammation}

Inflammatory biomarkers were available in a subsample of our cohort (IL-6: $\mathrm{n}=1,664$, hsCRP: $\mathrm{n}=2,219$, SAA: $\mathrm{n}=2,145$ and TNFR1: $\mathrm{n}=1,847)$. TNFR1 was independently associated with MMSE score (adjusted $\beta=-0.14$ per $1 \mathrm{ng} / \mathrm{ml}$; 95\% CI -0.23, -0.05); however, other inflammatory markers were not associated with MMSE score. MetS was associated with MMSE score even after adjusting for inflammatory markers and there were no interactions between inflammatory markers and MetS on MMSE score.

\section{Discussion}

In this multi-ethnic, urban, stroke-free, communitybased cohort, we found an inverse association between MetS and MMSE score, independent of other confounding factors. This association was limited to Hispanics and non-Hispanic whites, but did not vary by sex, age, education, medical insurance or inflammatory biomarkers.

The Metabolic Syndrome and Cognitive Performance
These findings have important public health implications. In the past two decades in the United States, the age-adjusted prevalence of MetS among adults increased from $23.7 \%$ (1988-1994) [18] to $34.4 \%$ (2003-2006) [19]. Based on the Census Projection of the US Population [20], in 2010, 77 million individuals above 20 years old have MetS, reaching 85 million by the year 2020. The difference in cognitive performance attributable to MetS might be small on an individual basis; however, due to the high MetS prevalence, the burden of impaired cognition due to the MetS may be substantial in the overall population.

Our findings showed similar results and magnitude confirming previous studies of the association between MetS and lower cognitive performance [21-24], and extend these findings to a predominantly Hispanic population in which the MetS prevalence is high. Hispanics have been traditionally understudied, although they are the fastest growing population in the US, they have the highest MetS prevalence, and together with non-Hispanic blacks, may be at a higher risk of dementia than non-Hispanic whites [25]. Studies of the relationship between vascular risk factors and cognition among Hispanics are therefore needed.

The negative effect of MetS on cognition has however not been observed in all populations. A European study [26] demonstrated better cognitive performance among women greater than 80 years of age with MetS. The LEIDEN 85-PLUS study [27] failed to demonstrate a difference in cognitive performance between individuals with and without MetS, and found slower cognitive decline among individuals over 85 years of age with MetS. The WHICAP study, which studied a similar demographic population, but older than our cohort (median 76 years of age), failed to demonstrate an association between MetS and incident dementia. However, it showed an association between diabetes and hyperinsulinemia, and increased incidence of Alzheimer disease and vascular dementia [28]. These results may be explained by survival bias, however, it is possible that people who live to old age with MetS either have a milder case or are not as affected by the syndrome.

The main hypothesis by which MetS is thought to affect cognition is through insulin resistance that can lead to cerebral small vessel disease. Both diabetes and hyperinsulinemia have been associated with increased risk of developing Alzheimer disease, vascular dementia [29] and cognitive decline. In addition, MetS is also associated with leukoaraiosis, a risk factor for worse cognitive performance [30] and cognitive decline [31].

There could also be direct independent effects of each of the MetS components themselves. Hypertension [4] and hyperlipidemia [32] are reported to increase the risk 
of dementia and/or cognitive decline. Advanced age has been associated with a greater prevalence of MetS and its components, which could further lead to an increase in cognitive dysfunction [26]. Similarly, diabetes has been associated with lower cognition [33], although we did not find an independent effect of diabetes after adjusting for other risk factors. Our results, moreover, support the utility of the concept of MetS as a syndrome, and suggest that considering the risk factors together may be more informative with regard to cognitive performance than each individual component. We did, however, find that HDL independently contributed to lower score on the MMSE, even after adjusting for other risk factors, though other risk factors did not. The relationship of lipids to cognition deserves further study. We did not consider the use of medications for lipids or blood pressure control because they were not part of the ATPIII definition of MetS.

Our models provide some support for the role of elevated inflammatory biomarkers in predicting poor cognitive performance. Elevated TNFR1 levels were associated with lower MMSE score in our cohort, but we did not confirm that the relationship between MetS and MMSE score was mediated through inflammation, as suggested by other studies [34]. Elevation of TNFR1 has also been associated with decreased memory performance [35] and it may be a reflection of the inflammatory mechanisms operative in atherosclerotic disease as it has been shown to be associated, in our cohort and others, with increased carotid plaque [36], left ventricular hypertrophy [16] and vascular dementia [37].

The reason for the apparent lack of effect of MetS among non-Hispanic blacks is uncertain. It is notable in this regard, however, that investigators in the Health $\mathrm{ABC}$ study [38] also failed to demonstrate decreased cognitive performance among African Americans with MetS, though they did demonstrate greater cognitive decline over time. It is possible that the absence of an effect of MetS on MMSE score among non-Hispanic blacks relates to a lower baseline MMSE score among non-Hispanic blacks. The MMSE has a substantial ceiling effect, however, such that there is more discrimination among individuals at lower scores than higher scores, making this explanation less likely. It is also possible, however, that our study and the other available studies did not have enough power to show an effect among non-Hispanic blacks alone. Alternatively, the results are the result of chance. Future studies on the race-ethnic variability of MetS in relation to cognition are warranted.

This study's strengths are the multi-ethnic cohort, including Caribbean Hispanics, a largely understudied population with a high burden of MetS; a large sample size; and the ability to control for multiple potential confounders. We addressed the MMSE in a continuous and categorical way, as well as the effects of diabetes, individual components of the MetS, and inflammation.

Our study also has limitations. First, the cross-sectional design does not allow us to make causal inferences. The MMSE has been demonstrated to have significant performance variability due to age, education, social status, ethnicity and language $[17,39]$. The MMSE thresholds utilized may have lower sensitivity and specificity among individuals with lower levels of education [40]. These cutoff scores are not very well documented in Hispanic elderly, however, because few studies have clinically validated the suspicion of cognitive impairment in Hispanics [17]. The majority of Hispanic participants in our study are of Caribbean origin; therefore our results may or may not be generalized to other Hispanic populations. Apolipoprotein genotype E4 was not routinely available in study participants, and therefore was not included in our models.

\section{Conclusion}

In summary, this study provides evidence of an inverse association between MetS and cognitive performance. This effect was found among Hispanics and nonHispanic whites, but not among non-Hispanic blacks. MetS as a cluster of risk factors appears to better translate the association with poor cognitive performance than its individual components or diabetes alone.

\section{Acknowledgments}

This work was supported by grants from the National Institute of Health/National Institute of Neurological Disorders and Stroke (NIH/NINDS R37 29993). We acknowledge the assistance and would like to thank Janet DeRosa, NOMAS project manager.

References

Vieira/Elkind/Moon/Rundek/ Boden-Albala/Paik/Sacco/Wright 
>3 Gami AS, Witt BJ, Howard DE, Erwin PJ, Gami LA, Somers VK, Montori VM: Metabolic syndrome and risk of incident cardiovascular events and death: a systematic review and meta-analysis of longitudinal studies. J Am Coll Cardiol 2007;49:403-414.

4 Knopman D, Boland LL, Mosley T, Howard G, Liao D, Szklo M, McGovern P, Folsom AR: Cardiovascular risk factors and cognitive decline in middle-aged adults. Neurology 2001;56:42-48.

5 Biessels GJ, Kappelle LJ: Increased risk of Alzheimer's disease in Type II diabetes: insulin resistance of the brain or insulin-induced amyloid pathology? Biochem Soc Trans 2005;33:1041-1044.

-6 Martins IJ, Hone E, Foster JK, Sunram-Lea SI, Gnjec A, Fuller SJ, Nolan D, Gandy SE, Martins RN: Apolipoprotein E, cholesterol metabolism, diabetes, and the convergence of risk factors for Alzheimer's disease and cardiovascular disease. Mol Psychiatry 2006;11:721-736.

$\checkmark 7$ Yaffe K, Weston AL, Blackwell T, Krueger KA: The metabolic syndrome and development of cognitive impairment among older women. Arch Neurol 2009;66:324-328.

8 Gatto NM, Henderson VW, St John JA, McCleary C, Hodis HN, Mack WJ: Metabolic syndrome and cognitive function in healthy middle-aged and older adults without diabetes. Neuropsychol Dev Cogn B Aging Neuropsychol Cogn 2008;15:627-641.

-9 Yaffe K, Haan M, Blackwell T, Cherkasova E, Whitmer RA, West N: Metabolic syndrome and cognitive decline in elderly Latinos: findings from the Sacramento Area Latino Study of Aging study. J Am Geriatr Soc 2007; 55:758-762.

10 Boden-Albala B, Sacco RL, Lee HS, Grahame-Clarke C, Rundek T, Elkind MV, Wright C, Giardina EG, DiTullio MR, Homma S, Paik MC: Metabolic syndrome and ischemic stroke risk: Northern Manhattan Study. Stroke 2008;39:30-35.

- 11 Folstein MF, Folstein SE, McHugh PR: 'Mini-mental state'. A practical method for grading the cognitive state of patients for the clinician. J Psychiatr Res 1975;12:189-198.

12 Wright CB, Elkind MS, Rundek T, Boden-Albala B, Paik MC, Sacco RL: Alcohol intake, carotid plaque, and cognition: the Northern Manhattan Study. Stroke 2006;37:1160-1164.

13 Rundek T, Sacco RL: Risk factor management to prevent first stroke. Neurol Clin 2008;26:1007-1045.

14 Boden-Albala B, Litwak E, Elkind MS, Rundek T, Sacco RL: Social isolation and outcomes post stroke. Neurology 2005;64: 1888-1892.

-15 Elkind MS, Luna JM, Moon YP, Liu KM, Spitalnik SL, Paik MC, Sacco RL: High-sensitivity c-reactive protein predicts mortality but not stroke: the Northern Manhattan Study. Neurology 2009;73:1300-1307.
Takei Y, Di Tullio MR, Homma S, Boden-Albala B, Rundek T, Sacco RL, Berry G, Liu R, Jin Z, Eguchi K, Elkind MS: Soluble tumor necrosis factor receptor 1 level is associated with left ventricular hypertrophy: the northern Manhattan study. Am J Hypertens 2009; 22:763-769.

17 Black SA, Espino DV, Mahurin R, Lichtenstein MJ, Hazuda HP, Fabrizio D, Ray LA, Markides KS: The influence of noncognitive factors on the Mini-Mental State Examination in older Mexican-Americans: findings from the Hispanic EPESE. J Clin Epidemiol 1999;52:1095-1102.

18 Ford ES, Giles WH, Dietz WH: Prevalence of the metabolic syndrome among US adults: findings from the third National Health and Nutrition Examination Survey. JAMA 2002; 287:356-359.

19 Ervin RB: Prevalence of metabolic syndrome among adults 20 years of age and over, by sex, age, race and ethnicity, and body mass index: United States, 2003-2006. National Health Statistics Reports.

20 U.S. Census Bureau Population Division: Projections of the population and components of change for the United States: 2010 to 2050 (np2008-t1). US Population Projections.

21 Dik MG, Jonker C, Comijs HC, Deeg DJH, Kok A, Yaffe K, Penninx BW: Contribution of metabolic syndrome components to cognition in older individuals. Diabetes Care 2007;30:2655-2660.

22 Liu CY, Zhou HD, Xu ZQ, Zhang WW, Li XY, Zhao J: Metabolic syndrome and cognitive impairment amongst elderly people in Chinese population: a cross-sectional study. Eur J Neurol 2009;16:1022-1027.

23 Akbaraly TN, Kivimaki M, Shipley MJ, Tabak AG, Jokela M, Virtanen M, Marmot MG, Ferrie JE, Singh-Manoux A: Metabolic syndrome over 10 years and cognitive functioning in late midlife: the Whitehall Study II. Diabetes Care 2010;33:84-89.

-24 Segura B, Jurado MA, Freixenet N, Albuin C, Muniesa J, Junque C: Mental slowness and executive dysfunctions in patients with metabolic syndrome. Neurosci Lett 2009;462:49-53.

25 Gurland BJ, Wilder DE, Lantigua R, Stern Y, Chen J, Killeffer EHP, Mayeux R: Rates of dementia in three ethnoracial groups. Int J Geriatr Psychiatry 1999;14:481-493.

26 Laudisio A, Marzetti E, Pagano F, Cocchi A, Franceschi C, Bernabei R, Zuccalà G: Association of metabolic syndrome with cognitive function: the role of sex and age. Clin Nutr 2008;27:747-754.

27 van den Berg E, Biessels GJ, de Craen AJM, Gussekloo J, Westendorp RGJ: The metabolic syndrome is associated with decelerated cognitive decline in the oldest old. Neurology 2007;69:979-985.
28 Muller M, Tang MX, Schupf N, Manly JJ, Mayeux R, Luchsinger JA: Metabolic syndrome and dementia risk in a multiethnic elderly cohort. Dement Geriatr Cogn Disord 2007;24:185-192.

29 Launer LJ: Demonstrating the case that AD is a vascular disease: epidemiologic evidence. Ageing Res Rev 2002;1:61-77.

30 Wright CB, Festa JR, Paik MC, Schmiedigen A, Brown TR, Yoshita M, DeCarli C, Sacco $\mathrm{R}$, Stern Y: White matter hyperintensities and subclinical infarction: associations with psychomotor speed and cognitive flexibility. Stroke 2008;39:800-805.

31 Park K, Yasuda N, Toyonaga S, Yamada SM, Nakabayashi H, Nakasato M, Nakagomi T, Tsubosaki E, Shimizu K: Significant association between leukoaraiosis and metabolic syndrome in healthy subjects. Neurology 2007;69:974-978.

32 Yaffe K, Barrett-Connor E, Lin F, Grady D: Serum lipoprotein levels, statin use, and cognitive function in older women. Arch Neurol 2002;59:378-384.

$>33$ Kanaya AM, Barrett-Connor E, Gildengorin G, Yaffe K: Change in cognitive function by glucose tolerance status in older adults: a 4-year prospective study of the Rancho Bernardo study cohort. Arch Intern Med 2004; 164:1327-1333.

34 Yaffe K: Metabolic syndrome and cognitive disorders: is the sum greater than its parts? Alzheimer Dis Assoc Disord 2007;21:167171.

-35 Haensel A, Bardwell W, Mills P, Loredo J, Ancoli-Israel S, Morgan E, Heaton R, Dimsdale J: Relationship between inflammation and cognitive function in obstructive sleep apnea. Sleep Breath 2009;13:35-41.

$>36$ Elkind MS, Cheng J, Boden-Albala B, Rundek T, Thomas J, Chen H, Rabbani LE, Sacco RL, Thrift AG: Tumor necrosis factor receptor levels are associated with carotid atherosclerosis. Stroke 2002;33:31-38 (including editorial comment).

37 De Luigi A, Fragiacomo C, Lucca U, Quadri P, Tettamanti M, Grazia De Simoni M: Inflammatory markers in Alzheimer's disease and multi-infarct dementia. Mech Ageing Dev 2001;122:1985-1995.

-38 Yaffe K, Kanaya A, Lindquist K, Simonsick EM, Harris T, Shorr RI, Tylavsky FA, Newman AB: The metabolic syndrome, inflammation, and risk of cognitive decline. JAMA 2004;292:2237-2242.

-39 O'Connor DW, Pollitt PA, Treasure FP, Brook CP, Reiss BB: The influence of education, social class and sex on Mini-Mental State scores. Psychol Med 1989;19:771-776.

40 Ostrosky-Solis F, Lopez-Arango G, Ardila A: Sensitivity and specificity of the Mini-Mental State Examination in a Spanish-speaking population. Appl Neuropsychol 2000;7:2531. 